\title{
Combustion and Emissions Characteristics of Diesel Engine Operating on Composite Combustion Mode of DME and Diesel
}

\author{
Junfa Duan \\ School of Mechanical Engineering, North China University of Water \\ Resources and Electric Power, Zhengzhou, China, 450011 \\ duanjunfa@126.com \\ Zhenzhong Yang \\ School of Mechanical Engineering, North China University of Water \\ Resources and Electric Power, Zhengzhou, China
}

\author{
Yongsheng Sun \\ School of Mechanical Engineering, North China University of Water \\ Resources and Electric Power, Zhengzhou, China \\ Zhiqiang Sun \\ School of Mechanical Engineering, North China University of Water \\ Resources and Electric Power, Zhengzhou, China
}

fuels can reduce sote and NOx emissions of diesel engines. Konno et al studied the law of the NO emissions in the engines using $\mathrm{DME}^{[1]}$. The studies by Cipolat $\mathrm{D}$ et al show that using DME as ignition material can improve the combustion of compression ignition engines ${ }^{[1]}$.

Zhang Junjun et al from Shanghai Jiaotong University, simulated the combustion of DME in a turbocharged diesel engine with a transformed fuel supply system. Their simulations and experiments show that the NOx emissions of $\mathrm{DME}$ engines have decreased significantly compared to diesel engines while the $\mathrm{HC}$ and $\mathrm{CO}$ emissions maintain a very low level and the sote emissions are nearly zero. However there appears decline of engine power ${ }^{[1]-[1]}$. Wang Ying et al from Xi'an Jiaotong University carried out an experimental study on the composite combustion mode of DME and diesel PCCI-DI. They found that the sote and NOx emissions wrer deduced under small load conditions fueled by diesel blended with a certain proportion of DME ${ }^{[1][1]}$.

Pure DME, lower in viscosity and combustion value, can cause lower engine output. However, engines fueled by diesel blended with DME can combine both the high output and fuel economy of pure diesel engines and lower sote and $\mathrm{NOx}$ emissions. This paper, based on experiments with the combustion system of diesel blended with DME, explores the combustion and emissions characteristics of the engines powered by blended fuel at the commonly used speed and under different load.

\section{Physiochemical PROPERTIES OF FUEL AND THE COMBUSTION SYSTEM}

DME is a gas, colorless, with slight ether smell, non-corrosive and almost non-toxicUnder normal temperature and pressure.The main physiochemical properties of DME and diesel are shown in Table 1. 
TABLE 1 PHYSICOCHEMICAL PROPERTIES OF DME AND DIESEL ${ }^{[1]}$

\begin{tabular}{|c|c|c|}
\hline Property & DME & Diesel \\
\hline Chemical Formula & CH3-O-CH3 & CxHy \\
\hline Boiling Point ( $\left.{ }^{\circ} \mathrm{C}\right)$ Boiling Point & -24 & - \\
\hline Evaporating Pressure(MPa) & $0.45\left(20^{\circ} \mathrm{C}\right)$ & - \\
\hline Liquie Viscosity(cP) & 0.15 & $4.4-5.4$ \\
\hline LHV(MJ.kg ${ }^{-1}$ ) & 28.43 & 42.5 \\
\hline Ignition Temperature $\left({ }^{\circ} \mathrm{C}\right)$ & 235 & 250 \\
\hline Cetane Number & $55-65$ & 45 \\
\hline Equivalent air-fuel ratio & 9 & 14.3 \\
\hline $\begin{array}{c}\text { Latent heat of vaporization } \\
\left(\mathrm{kJ} . k g^{-1} \text { ) }\right.\end{array}$ & $466\left(20^{\circ} \mathrm{C}\right)$ & 290 \\
\hline
\end{tabular}

DME, due to a very low boiling point and high evaporation pressure, can, at room temperature, rapidly blend with air to form a combustible mixture. DME, with a lower self-ignition temperature, high cetane number and short ignition delay period, is prone to compression ignition while the combustion pressure rise rate is low. As a result, DME can start self-ignition first which then ignites diesel. In this way the combustion duration can also be shortened.

Since DME is in a gaseous state at room temperature, the combustion system, referred in this paper, is designed with an injection of DME into the intake pipe. The gasification of DME partly starts in the intake pipe and continues into the cylinder to form an approximate homogeneous charge. The diesel injection, getting through the original fuel supply system directly into the cylinder starts atomization and partial premixing under high pressure. At the end of compression stroke, when the cylinder temperature reaches the self-ignition point of DME, DME starts homogeneous charge compression ignition causing the rapid temperature rise inside the cylinder and then leading to the spontaneous combustion of diesel. An independent supply system respectively for DME and diesel is designed to regulate the supply through adjusting the injection pressure and pulse width.

\section{EXPERIMENT DEVICE AND METHOD}

\section{A. Engine}

The experiment is conducted on a four-cylinder high-pressure common rail, turbocharged intercooled diesel engine with EGR direct injection, of which the main technical parameters are shown in Table 2. During the experiment, the fuel temperature is controlled by the fuel temperature control device at no higher than $40{ }^{\circ} \mathrm{C}$. The temperature intercooled after air intake is maintained by the cooling control unit at no higher than $50{ }^{\circ} \mathrm{C}$. The engine cooling water temperature at the outlet is maintained at about $80{ }^{\circ} \mathrm{C}$.The lubricant temperature is maintained at about $90{ }^{\circ} \mathrm{C}$.
TABLE 2 THE MAIN TECHNICAL PARAMETERS OF THE DIESEL ENGINE

\begin{tabular}{|c|c|}
\hline Items & Parameters \\
\hline Number of Cylinders & $\begin{array}{c}\text { four-cylinder, turbo, exhaust } \\
\text { gas recirculation }\end{array}$ \\
\hline Cylinder Diameter ( mm ) & 4 \\
\hline Stroke ( mm ) & 83.1 \\
\hline The connecting rod length \\
(mm) & 92 \\
\hline Displacement ( L ) & 145.8 \\
\hline The number of injector holes & $16.7: 1$ \\
\hline Compression ratio & 110 \\
\hline Rated power ( kW ) & 4000 \\
\hline Rated Speed ( r/min ) & 310 \\
\hline Maximum torque ( N.m ) & $1800 \sim 2800$ \\
\hline The maximum torque speed \\
( r/min )
\end{tabular}

\section{B. Experiment Equipment}

The main equipment and instruments used for the experiment include: PC2000 eddy current dynamometer and measurement control system; KiBox combustion analyzer; MEXA-7100D gas emissions tester, DISMOKE 4000 opacity smoke meter, XK3100-B2 + high-precision electronic scale; ECU data control and monitoring systems.

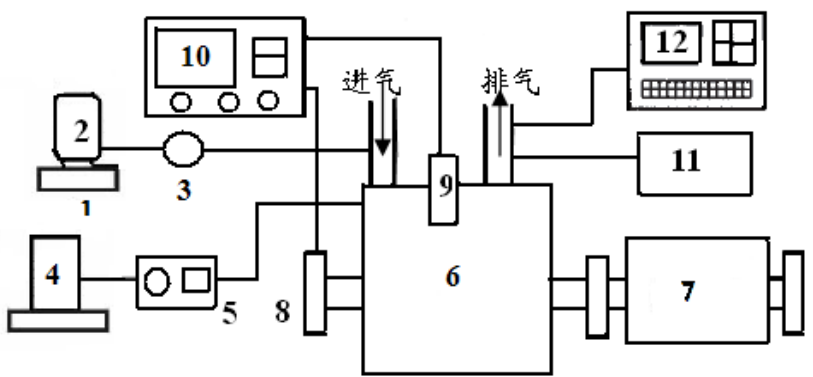

1. Electronic scale 2.DME tank 3.Pressure adjust valve 4 . Diesel fuel tank 5.Fuel comsumption meter 6. Engine 7. Eddy current dynamometer 8.Crankangle sensor 9. Pressure sensor 10. Combustion analyzer 11. Opacity smoke meter 12 . Exhaust gas analyzer

Fig. 1 Schematic diagram of experimental setup

This experiment uses a dual fuel supply system: diesel going over a high-precision fuel consumption instrument through low pressure, high pressure pump into the common rail; DME from the tank regulated through the pressure regulating valve to about $0.2 \mathrm{MPa}$, being led into the intake pipe for rapid vaporization and mixing with air to form a premixed gas, which then enters through the intake manifold into each cylinder. The schematic of the experiment equipment and system is shown in figure 1.

\section{EXPERIMENT RESULTS AND ANALYSIS}

At the experiment, the engine respectively operates in the 
composite combustion mode of DME HCCI and diesel DI and in the pure diesel DI combustion mode. With the engine maintaining a speed of 2000rpm, the characteristics of the engine combustion and emissions are analyzed. The supply of DME in the experiment is regulated through the adjustment of supply pressure, the supply of diesel through the adjustment of injection pulse width.

\section{A. Combustion Characteristics}

It is seen from Figure 2 that in the composite combustion mode of DME PCCI and diesel DI the maximum cylinder burst pressure is $10.7 \mathrm{Mpa}$ and the correspondent crank angle $1.9^{\circ} \mathrm{CA}$ after TDC. In the DI combustion mode, the maximum cylinder burst pressure is $9.0 \mathrm{Mpa}$ and the correspondent crank angle $0.6^{\circ} \mathrm{CA}$ after TDC. Obviously the peak pressure of the former is bigger than the latter, but the peak of the former comes later. This occurs because the DME before entering from the intake pipe into the cylinder already forms a homogeneous mixture and with a low self-ignition temperature DME combustion starts before the TDC in the compression process. However, the maximum burst pressure in the composite combustion mode appears slightly delayed .

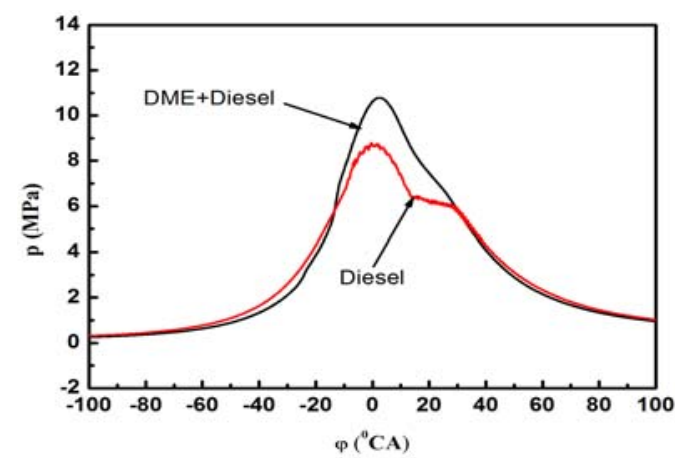

Fig. 2 Cylinder pressure versus crank angle

It is seen from Figure 2 that the pressure rise rate curve of DME PCCI and diesel DI composite combustion mode is largely different from that of the pure diesel DI combustion mode. In the former mode the peak pressure rise rate is $0.732 \mathrm{MPa} /{ }^{\circ} \mathrm{CA}$ and in the latter $0.527 \mathrm{MPa} /{ }^{\circ} \mathrm{CA}$. And the peak rate moment moves from $8.2^{\circ} \mathrm{CA}$ before TDC to $12.7^{\circ} \mathrm{CA}$ before TDC. This is due to the homogeneous mixture of DME and air formed in the intake pipe having a high cetane number causing premature combustion at the end of the compression stroke. Therefore, when the engine operated in the composite combustion mode, the supply amount of DME should not be too large. Otherwise, the engine will run roughly with a decline of power performance and fuel economy.

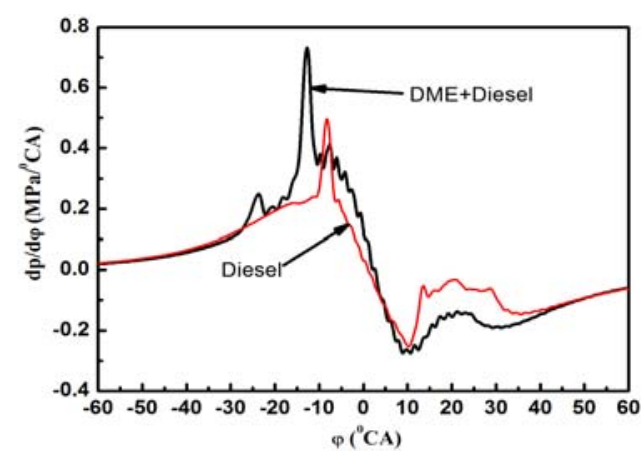

Fig. 3 Cylinder pressure rise rate versus crank angle

It is seen from Figure 3 that the cylinder temperature in the composite combustion mode is lower than in the diesel DI mode when crankangle less the $15^{\circ} \mathrm{CA}$ before TDC. When the compression pressure is between $15^{\circ} \mathrm{CA}$ before TDC and $30^{\circ} \mathrm{CA}$ after TDC, the cylinder temperature in the composite combustion mode is higher than that in the diesel DI mode. When the compression pressure is higher than around $30^{\circ} \mathrm{CA}$ after TDC, the cylinder temperature of the composite combustion mode is lower than that of the diesel DI mode. The maximum average cylinder temperature in both the combustion modes appears when the compression pressure is higher than $30^{\circ} \mathrm{CA}$ after TDC. The maximum temperature of the diesel DI mode of $1650 \mathrm{~K}$ is higher than the $1600 \mathrm{~K}$ of the composite combustion mode.

Figure 4 shows a big difference between the heat release rate of the composite combustion mode and that of the diesel DI mode. The heat release in the composite combustion mode involves three stages. The first stage features low-temperature combustion with the compression pressure being between $30^{\circ} \mathrm{CA}$ and $20^{\circ} \mathrm{CA}$ before TDC. With the cylinder temperature increasing starts the second stage when DME and pilot diesel injection get mixed and ignited with the compression pressure being between $20^{\circ} \mathrm{CA}$ and $10^{\circ} \mathrm{CA}$ before TDC. It mainly involves the rapid oxidation of DME and then its pre-mixed combustion with the pilot injected diesel. The combustion process in this stage is of a short duration and has a higher heat release peak. The third stage is the combustion after diesel injection. The heat released by the diesel DI combustion contains two parts: the first part is released by the pilot injection of the first stage, the second part by the main injection.

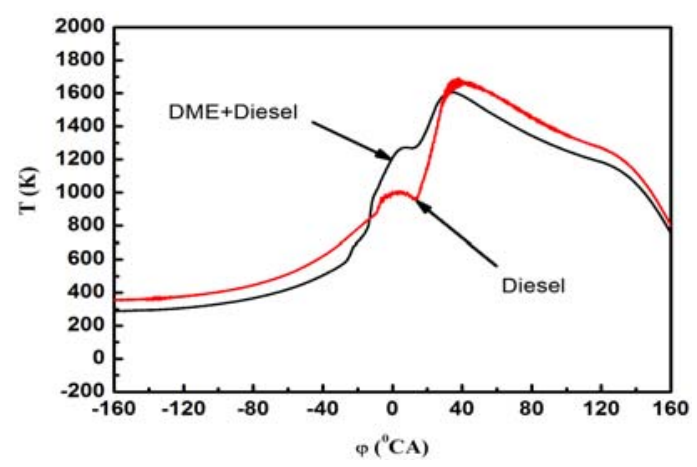

Fig. 4 Mean combustion temperature versus crank angle 


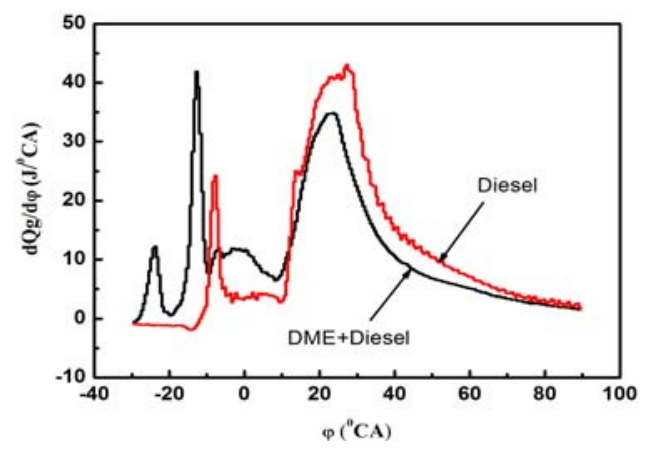

Fig. 5 Heat release rate versus crank angle

\section{B. Emission Characteristics}

Figure 6 is about the NOx Emissions under different loads. Under various conditions, the composite combustion has lower NOx emissions than the pure diesel combustion. It is mainly due to the higher latent heat of DME vaporization in the composite combustion mode, which reduces the cylinder temperature at the early combustion stage. And owing to the lower calorific value of DME combustion, the cylinder temperature of DME combustion is lower than that of pure diesel combustion. When the DME air premixed volume maintaining at $1.89 \mathrm{~kg} / \mathrm{h}$, as the load increases, the NOx emission is largely reduced. This may be because the exhaust gas recirculation under a large load has large impact on on the homogeneous DME charge compression combustion.

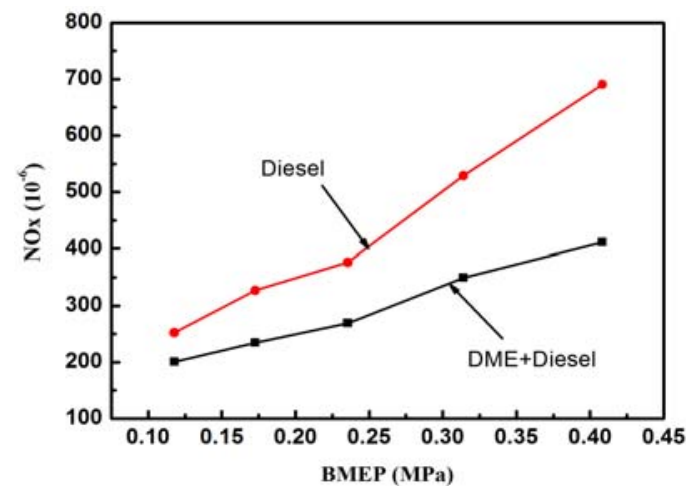

Fig. 6 NOx versus engine load

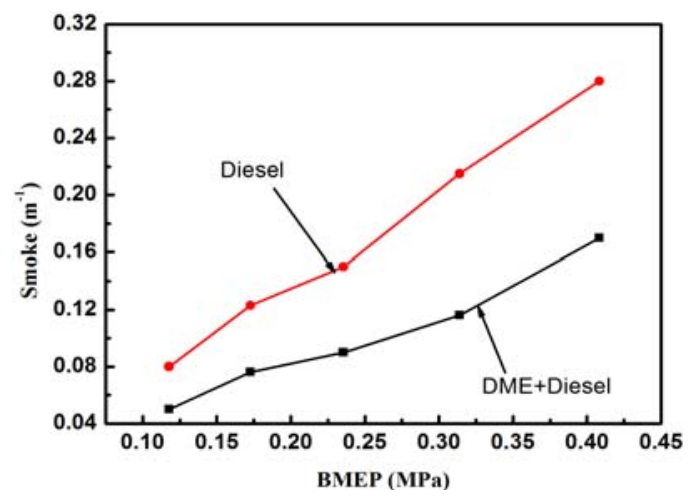

Fig. 7 Sote versus engine load
Figure 7 is the smoke emission curves with load variation in the two combustion modes. The figure shows that the emissions in the composite combustion mode are only about $50 \%$ of the emissions in the diesel DI mode. It is because DME, lacking C-C bond in its molecular structure, breaks down easily for oxidation reaction of combustion. As a result it is not easy to form carbon smoke nuclei. And it is easy for DME, with higher oxygen content, to complete oxidation of C. Under heavy load conditions, the DME HCCI facilitates the diffusion and combustion of diesel. In this way the smoke emissions in composite combustion mode are much lower than that in the diesel DI mode.

\section{CONCLUSION}

(1) The composite combustion mode of DME HCCI and diesel DI has a higher maximum peak pressure and a lower maximum combustion temperature than the pure diesel combustion mode. The composite combustion mode of DME HCCI and diesel DI is characterized by a 3-stage heat release process. The first stage involves the homogeneous compression combustion of DME and air. The second stage involves besides the homogeneous compression combustion of DME and air also the pre-mixed combustion of pilot diesel injection. The third stage involves the pre-mixed and diffusion combustion of diesel injection.

(2) The composite combustion mode of DME HCCI and diesel DI, when the premixed DME intake being maintained at a certain amount, can effectively reduce NOx and smoke emissions.

\section{REFERENCES}

[1] Westbrook CK. Chemical kinetic modeling of oxygenated diesel fuels in advanced petroleum-based and alternative fuels. DOE Report; 1999.

[2] Ogawa H, Miyamoto N, Yagi M. Chemical-kinetic analysis on PAH formation mechanisms of oxygenated fuels. SAE Paper 2003-01-3190, SAE Transanctions Journal of Fuels and Lubricants, 2003. 112(4):2413-21.

[3] Cipolat D., N. Bhana, Fuelling of a compression ignition engine on ethanol with DME as ignition promoter: Effect of injector configuration. Fuel Processing Technology, 2009.

[4] Konno, M., Kajitani, S., Oguma, M., Iwase, T., Shima, K. NO emission charactheristics of a CI engine fueled with neat DME [C]. SAE Paper 1999-01-1116, 1999.

[5] J-J Zhang, Z Huang, J-H Wu, X-G Qiao, and J-H Fang. Combustion and Performance ofHeavy-Duty Diesel Engines Fueled With DME. Proceedings of the Institute ofMechanical Engineers, Part D, Journal of Automobile Engineering, 2008.

[6] Junjun Zhang, Xinqi Qiao, Bin Guan, Zhen Wang, Guangfei Xiao, Zhen Huang. Search forthe Optimizing Control Method of Composite Charge Compression Ignition (CCCI) Combustionin an Engine Fueled with DME. Energy \& Fuels, 2008.

[7] Junjun Zhang, Xinqi Qiao, Zhen Wang, Bin Guan, Zhen Huang. An Experimental Investigation of Low Temperature Combustion (LTC) in an Engine Fueled with 二甲醚. Energy \& Fuels, 2009.

[8] Ying Wang, Zhenxiang Guo,Li He,Wei Li,Longbao Zhou.Study on PCCI-DI Combustion in DME Engine[J]. Transactions of CSICE,2008,26(4):319-324.

[9] Ying Wang,Jie Zhou, Li He,Zhenxiang Guo, Longbao Zhou.Investigation on Effects of Cold EGR on Combustion and Emssion characteristics in DME PCCI-DI Engine. [J]. Chinese Internal Combustion Engine Engineering, 2010，31(4):17-20. 